\title{
Investigation of Luxury Values in Shopping Tourism Using a Fuzzy-Set Approach
}

Journal of Travel Research

2019, Vol. 58(I) 77-91

(C) The Author(s) 2017

Article reuse guidelines:

sagepub.com/journals-permissions DOI: $10.1177 / 0047287517741005$ journals.sagepub.com/home/jtr

@SAGE

\author{
Antonia Correia', Metin Kozak², and Seongseop (Sam) Kim ${ }^{3}$
}

\begin{abstract}
This exploratory study, based on 316 questionnaires completed by mainland Chinese tourists in Hong Kong, investigates whether certain conditions are sufficient to motivate tourists' decisions to buy luxury products. The results of fuzzy-set qualitative comparative analysis reveal that a combination of four conditions (emotional attachment, fashion leadership, prestige sensitivity, and social value) is sufficient to influence tourists to shop for luxury brands. It must be pointed out, however, that the four conditions are unnecessary in some social and shopping contexts, and thus the findings do not reject the possibility that alternative conditions may also influence luxury shopping decisions. This study using fuzzy-set theory demonstrates that tourists who score highly in all four conditions constitute an almost perfect subcategory of luxury shoppers. Therefore, it is recommended that other scholars examine the conditions that are sufficient to influence tourists rather than concentrating on other factors.
\end{abstract}

\section{Keywords}

luxury shopping, shopping tourism, shopping behavior, Chinese tourists, Hong Kong

In today's consumer-oriented world, tourists and shoppers seek value in goods that are both novel and exotic (Choi, Heo, and Law 2016; Kozak, Correia, and Del Chiappa 2016). Luxury or upscale travel offerings provide tourists with what they desire (Bakker 2005; Correia, Kozak, and Reis 2016), allowing them to meet their need for self-actualization, to create a more idealized self-image (Danziger 2006), and to impress others (Mason 1981). Luxury evokes exclusivity, and offers tourists a high social status, a personalized experience, and high levels of comfort and convenience (Chen and Peng 2014; Kurtz 2004). Luxury tourists do not necessarily seek the best price, but rather the best-quality products and the most complete spectrum of services (Ikkos 2003; Yang and Mattila 2014, 2017).

The consumption of luxury goods in mainland China has risen through shopping in recent years because of the rising economic power and its citizens' primary focus on materialism (Tsai, Yang, and Liu 2013; Wong and Ahuvia 1998). For example, the Hong Kong Tourism Board (2015) reports overnight visitor spending of US\$940 per capita. On average, 58.4 percent (US\$550) of that amount is spent on shopping, which constitutes the single largest percentage of total spend. In 2015, tourists to mainland China spent US $\$ 292$ billion. Of that amount, U.S. tourists spent US $\$ 113$ billion, German tourists US\$78 billion, and U.K. tourists US\$63 billion (UNWTO 2016). These figures are growing at an average rate of 8.5 percent relative to 2013 , and no decrease is expected in the foreseeable future. The UN World Tourism Organization (UNWTO 2015) anticipates that in 2025
Chinese tourists will spend US\$130 million on shopping while traveling.

The rich or affluent Chinese shoppers are defined as those who have cash power through a successful business or the young generation who are raised like xiaohuangdi (little emperor) following the one-child family policy and take over their parents' fortune (He 2017). In addition, the affluent masses and those who aspire to be rich, as opposed to the very wealthy, are attracted to products that are recognized as being expensive to dazzle and outshine their peers (Choi, Heo, and Law 2016). It is known that affluent Chinese consumers are all nouveau riche (Wong 2007). The benefits sought from luxury consumption can also help to fulfill both aesthetic and self-actualization needs ( $\mathrm{Zhu}, \mathrm{Xu}$, and Jiang 2016). The luxury shopping is therefore the major motivation for Chinese consumers' decision to travel abroad ( $\mathrm{Li}$ et al. 2011).

China's transition to a market economy has sparked a fascination for branded luxury products in Chinese consumers because such products are seen as providing instant proof of

\footnotetext{
'CEFAGE, University of Algarve and Universidade Europeia, Faro, Algarve, Portugal

${ }^{2}$ Dokuz Eylul University, Izmir, Turkey

${ }^{3}$ Hong Kong Polytechnic University, Hong Kong, SAR China

Corresponding Author:

Metin Kozak, School of Tourism and Hospitality Management, Dokuz Eylul University, Foca, Izmir, 35000, Turkey.

Email: m.kozak@superonline.com
} 
wealth and success (Bonetti 2014; Zhu, Xu, and Jiang 2016). Chinese tourists travel the world to benefit from value-formoney deals, and bargain for the pleasure of involvement with other cultures (Agrusa, Kim, and Wang 2011; Chan, To, and Chu 2015; Gao, Huang, and Brown 2017). As Chinese tourists tend to privilege market accessibility, Hong Kong is their destination of choice for luxury shopping. Tourism is a major contributor to the Hong Kong economy.

This study focuses on mainland Chinese tourist shopping in Hong Kong, which is still considered the major luxury shopping market for that tourist population (He 2017). Wong and Ahuvia (1998) suggest that Chinese people's motivation to buy luxury brands has its roots in the culture of Confucianism, under the influence of which behavior is driven primarily by social conformity and a concern with social display. Understanding the cultural roots of the shopping behavior of modern wealthy Chinese consumers calls for research (Chan, To, and Chu 2015; Degen 2009; Choi, Heo, and Law 2016; $\mathrm{Zhu}, \mathrm{Xu}$, and Jiang 2016), of which the present study is an example. The traditional Confucian value system is based on eight virtues: faithfulness, filial piety, benevolence, love, courtesy, loyalty, frugality, and a sense of shame. These are the moral pillars that dictate Chinese social behavior, including consumer behavior. The behavior of the prosperous Chinese consumer is influenced by the Confucian values of collectiveness and family, respect and superiority, and glory and awareness of shame (Hsu and Huang 2016; Lu 2008).

In analyzing the components of the Confucian value system, some researchers have posited that the individualistic structure of Western culture and group-oriented structure of East Asian culture are the root cause of the differences in luxury shopping behavior between them (Tsai, Yang, and Liu 2013; Wong and Ahuvia 1998). Chinese culture is prone to outrageous consumption (Zhan and He 2012), despite the Chinese valuing their relationships with others and their own social standing (e.g., Bian and Forsythe 2012; Choi, Heo, and Law 2016; Hsu and Huang 2016; Zhang and Kim 2013) because, in the Chinese system, social standing is achieved through material possessions (e.g., Bonetti 2014; Chen and Peng 2014; Ngai and Cho 2012; Wong and Ahuvia 1998; Zhu, Xu, and Jiang 2016).

This study examines the nature of luxury buying behavior, with a focus on tourist perceptions of luxury shopping. The aim of such analysis is to capture the complete continuum of attitudes of each respondent rather than leveraging those attitudes discretely. A configurational design comprising four causal conditions leading to shopping for luxuries in Hong Kong is tested to determine the value of those conditions in different social contexts and shopping modes. In the methodological approach, this study adopts fuzzy-set analysis, which has been not actively used in the tourism research field.

\section{Literature Review}

Luxury shoppers are driven primarily by the positive emotions deriving from the possession of prestigious brands or the offer of exclusive experiences (Kapferer 2015). Earlier, Veblen's (1899) conceptualization of conspicuous consumption places the accent on the display of status through possessions (Correia, Kozak, and Reis 2016). Furthermore, Vigneron and Johnson (1999) identify a set of value dimensions that drive luxury consumption, such as social acceptance, emotional attachment, and quality assurance. In addition, many studies have discussed the definition of luxury, luxury shopping, the motivations or values of luxury shopping, and attitudes toward luxury shopping (e.g., Yoo and Park 2016; Lee and Watkins 2016; Correia and Kozak 2016; Correia, Kozak, and Kim 2017; Wiedmann, Hennigs and Siebels 2007a). Therefore, this section reviews a range of previous studies.

This driver refers to the perception that buying expensive items serves as a signal to others of one's social standing and status (Lichtenstein, Ridgway, and Netemeyer 1993). Hence, prestige sensitivity indicates the social meaning of a consumer's shopping traits (Lichtenstein, Ridgway, and Netemeyer 1993). Jin and Sternquist (2004) argue that price is connected to prestige when price is related to brand consciousness. Consumers of high-priced, famous brand names attempt to achieve social standing by possessing them in a way that signals their prestige to society (Jin and Sternquist 2004). The consumption of high-priced items or famous brand names is perceived as a way of enhancing one's selfimage and being accepted by peers. Bian and Forsythe (2012) demonstrate that in purchasing luxury brands Chinese shoppers are seeking exclusivity to avoid similarity with others.

In a similar vein, some researchers (Ngai and Cho 2012; Tsai, Yang, and Liu 2013) report that Chinese youths buy luxury products to communicate brand value and to foster social recognition and acceptance by their peers. Zhan and He (2012) discuss middle-class Chinese consumers' tendency to perceive luxury brands as vehicles for meeting social expectations and obtaining positive recognition from others. In addition, Jain, Roy, and Ranchhod (2015) find that young Indian consumers perceive self-expression and the consumption of luxury goods to be the main consumption values of luxury shoppers. A study by Peshkova, Urkmez, and Wagner (2016) finds that Russian upper-middle-class consumers perceive luxury fashion goods to be symbols of prestige and social status. Prestige sensitivity is thus assumed to drive luxury shopping behavior.

\section{Fashion Leadership}

Fashion is also related to self-image, with consumers conveying their self-concept or self-image through fashion (Kaiser 1990), which in turn serves as a strategy for impressing others (Goldsmith, Heitmeyer, and Freiden 1991). A fashion leader is conceptualized as "a consumer who has a greater than average interest in fashion, [who] purchases new ... fashions relatively earlier than the rest of the market, and who influences later buyers to purchase new fashion items" 
(Goldsmith, Heitmeyer, and Freiden 1991, 38). Such a consumer is aware of new trends and seeks to influence others (Goldsmith, Heitmeyer, and Freiden 1991; Workman and Kidd 2000) as a way of strengthening his or her self-esteem and social status (Shim and Bickle 1994). Fashion leaders are also much more likely than other consumers to seek out new shopping experiences, for instance by shopping in famous stores (Rovai 2016a; Shim and Bickle 1994).

Fashion products have a symbolic meaning that elicits strong emotional attachment (Holbrook and Hirschman 1982). In a study of purchases of Louis Vuitton products on social media sites, Kim and Ko (2012) identify fashion leadership as the main motivator of such purchases, suggesting that fashion leadership has marketing implications for online shoppers. According to Hudders et al. (2014), female shoppers exhibit a strong preference for luxury clothes to avoid feelings of competitiveness. Hence, the symbolic value of luxury fashion products may enhance the self-image and social status of tourists.

\section{Social Value}

Sweeney and Soutar $(2001,211)$ define social value as "the utility derived from [a] product's ability to enhance [a consumer's] social self-concept." Such value refers to the need to conform, particularly with reference groups (Bearden and Etzel 1982; Moschis 1976). The rule in consumption is to have what others have to conform (Leibenstein 1950) or to gain approval. Park and Lessig (1977) characterize social value as the influence that others have on consumers' decisions owing to consumers' desires to be associated with their peers. The authors label that influence a value-expressive function. Bearden and Etzel (1982) argue that visible signs such as brands are important factors in a reference group's influence on purchasing decisions. Shukla and Purani (2012) identify diverse values (such as self-directed symbolic/ expressive values, other-directed symbolic/expressive values, utilitarian/functional values, and cost/sacrifice values) as the luxury value perceptions of British shoppers, whereas Indian shoppers are more reliant on other-directed symbolic/ expressive values and cost/sacrifice values. In the Hong Kong luxury shopping context, Chan, To, and Chu (2015) find that shoppers perceive the purchase of luxury goods to convey social status, and that this perception affects their repurchase intentions.

\section{Emotional Attachment}

Finally, emotional attachment refers to the utility derived from the affective states that purchasing a good provides for the consumer, such as beauty, aesthetics, enjoyment, and/or pleasure (Sweeney and Soutar 2001). Consumption is also an affective process in which symbolism, hedonism, and aesthetics play a crucial role (Holbrook and Hirschman 1982). That process is particularly evident in the luxury product market, as luxury products carry many intangible benefits (Vigneron and Johnson 1999). Tsai, Yang, and Liu (2013) document a tendency among Chinese consumers to purchase bandwagon luxury products to express in-group membership and the sharing of a similar lifestyle or social background with others. In the same vein, Kastanakis and Balabanis (2012) indicate that bandwagon consumption arises from perceptions of an interdependent self and socially approved creative deviations from the norm.

In a later study, Kastanakis and Balabanis (2014) look at conspicuous shoppers' desire to seek an independent self that is dissociated from other consumers who want to emulate them. Wu et al. (2015) find that young Taiwanese luxury consumers pursue pleasure by associating with friends who have a similar style and are easily persuaded by celebrity advertising. Jain, Roy, and Ranchhod (2015) identify emotional emulation among Indian luxury consumers, including self-consumption, fulfillment, self-expression, uniqueness, ego-boosting, enhanced aesthetic pleasure, and approval of design and style. Hamelin and Thaichon (2016) report that Moroccan women buy luxury goods to show off and attract the attention of their peers. Other studies show that buying luxury brands is fun and provides pleasure beyond the actual material purchase (e.g., Park and Reisinger 2009). Interestingly, it carrying or wearing luxury brands in a hotel offers some consumers positive emotions and pleasure (Chen and Peng 2014; Peshkova, Urkmez, and Wagner 2016). In summary, there is a large body of literature documenting the attainment of emotional value through the purchase of luxury commodities.

In sum, it is evident that consumption as a shopping value is closely related to motivation. In this study, based on the preceding literature review, prestige sensitivity, fashion leadership, emotional attachment, and social values are assumed to be the key drivers of luxury brand shopping for mainland Chinese tourists in Hong Kong. These social and psychographic values shape both the way that individuals perceive their surrounding environment and their consumption values. In addition, there is evidence that sociodemographic characteristics and the shopping context influence shopping attitudes (Kamal, Chu, and Pedram 2013; Kim, Timothy, and Hwang 2011; Morganosky 1990). In particular, in today's highly dynamic world of trade and consumption patterns, as consumers have become more irrational, the exclusivity of luxury products can now be changed through the influence of social media or snobbism (Lee and Watkins 2016). This may be particularly true for the younger generation who purchase these products because they want to conform or be associated with models and celebrities.

\section{Studies Using QCA}

Given that shopping behavior varies by the shopping context and multiple complex conditions, QCA is well-suited to demonstrating how all of the aforementioned luxury shopping 
values together influence such behavior. QCA was originally developed by Ragin (1987), and has since been adopted across a wide range of disciplines (De Meur and Rihoux 2002; Ragin 2014; Rihoux 2003), although its application in the tourism context remains limited (Woodside 2013). Among the few examples to date, Woodside, Hsu, and Marshall (2011) perform QCA to determine how national cultural values influence international tourist experiences. Their assumption is that national cultures are complex configurations of values rather than a collection of individual values (Kim and McKercher 2011). The authors argue that QCA is more appropriate for estimating the extent to which various configurative models explain tourists' experiences than correlations and multiple regressions that rely on symmetric analysis. In a more recent study, Woodside, Prentice, and Larsen (2015) conduct fuzzy-set QCA (fs QCA) to assess the service evaluations of tourists in Macau casinos. The authors state that the approach helped them to conclude that asymmetrical conditions represent the most valuable conditions for casinos, a conclusion that contradicted their previous analysis based on symmetrical causal relations.

D’Urso et al. (2016) use fuzzy-set theory to propose a new way of clustering tourism groups that allows group organization to emerge rather than being forced by the researcher. The theory also facilitates highly comprehensible segmentation. For example, Chua and Guo (2015) propose a new way of marking the axes in importance-performance analysis (IPA), namely, similarity-based IPA, that is supported by intuitionistic fuzzy sets. When applied to cycling tourism, their research also highlights the weaknesses of supporting IPA through analysis of the median, mode, or average in discrete Likert scales. Having examined other potential methods of analysis for researching a complex phenomenon such as shopping tourism, the authors conclude that QCA is best because of the holistic approach it affords.

\section{Conceptual Model and Research Proposal}

The conceptual model adopted in the study reported herein employs a QCA framework that allows assessment of the association between a given result and all possible Boolean groups of shopping values reported in the literature. QCA covers complex conjunctural cause-and-effect phenomena (Ragin 2014; Ragin and Rihoux 2004). It also assumes that a given phenomenon (output) is explained by a combination of conditions (independent variables) and that further different combinations of those conditions (independent variables) may produce the same outcome. QCA also assumes that in different contexts the combinations may exert a different effect on that outcome.

In general, such analysis assumes that different combinations of variables may lead to the same output (De Meur and Rihoux 2002). QCA is an analytical technique that allows a more holistic approach than other types of analysis. It is supported by a Boolean algorithm that permits the identification of parsimonious variables. Hence, by definition, it also removes from the set of configurational conditions any variables that lack significant explanatory power for a particular outcome. In other words, the explanation for that outcome should be supported by the fewest conditions necessary to explain it.

The logic behind the approach is to construct a truth table in which each case is represented by a certain combination of conditions ( 0 and 1$)$ leading to an outcome (also with 0 and 1 values). The final result is a configuration that has a combination of conditions to explain an outcome, and is obtained through a minimization problem solver that reduces the combinations of conditions to the minimum necessary to ensure the reliability of the explanation for the outcome. Accordingly, the outcome achieves the maximum level of parsimony possible in the given context (Ragin 2014).

The QCA framework adopted in this research uses set to label the variables to underscore that we are concerned with individuals' membership in a condition. In our case, the combination of individual sets, for instance, high emotional attachment, high social value perceptions, low fashion leadership, and low prestige sensitivity, is referred to as a configuration. The crisp-set case assumes that all sets are dichotomous indicators (where $0=$ fully out and $1=$ fully in). The sets are labeled, with uppercase letters signifying 1 (e.g., fully in A) and lowercase letters signifying 0 (e.g., fully out of A), usually represented as 1-A. The other notation used is "." to stand for the Boolean condition "and." The relationship between the predictors and outcome can be assessed with conditional probabilities, usually represented as $\operatorname{Pr}(\mathrm{Y} \mid$ A - B). In theoretical sets, the strongest conditional probability indicates the highest degree of empirical correspondence with "A - B is a subset of Y" or, in logic, "if A - B, then Y." The conceptual model depicted in Figure 1 illustrates the four configurations considered. It includes the four values hypothesized to work together to drive tourists to exhibit luxury shopping behavior while visiting Hong Kong. These values, which are derived from the literature, were first subjected to principal component analysis (PCA) to derive a single factor for each shopping value. The components derived from PCA were then scored on a three-point scale to preserve the median values needed to calibrate their standard ranks in a fuzzy-set design.

To arrive at this stage, it was also necessary to rescale the eigenvalues of the components derived from the three order points. These values were then assumed to be the antecedent conditions of the objective causal configurations associated with luxury shopping behavior during a stay in Hong Kong. The full sample was used to allow for the inclusion of all possible shopping alternatives. Because the technique uses a Boolean algorithm, the solution is the most common generalization of the outcome within a parsimonious solution. It is advisable with this type of analysis to assess all possible 

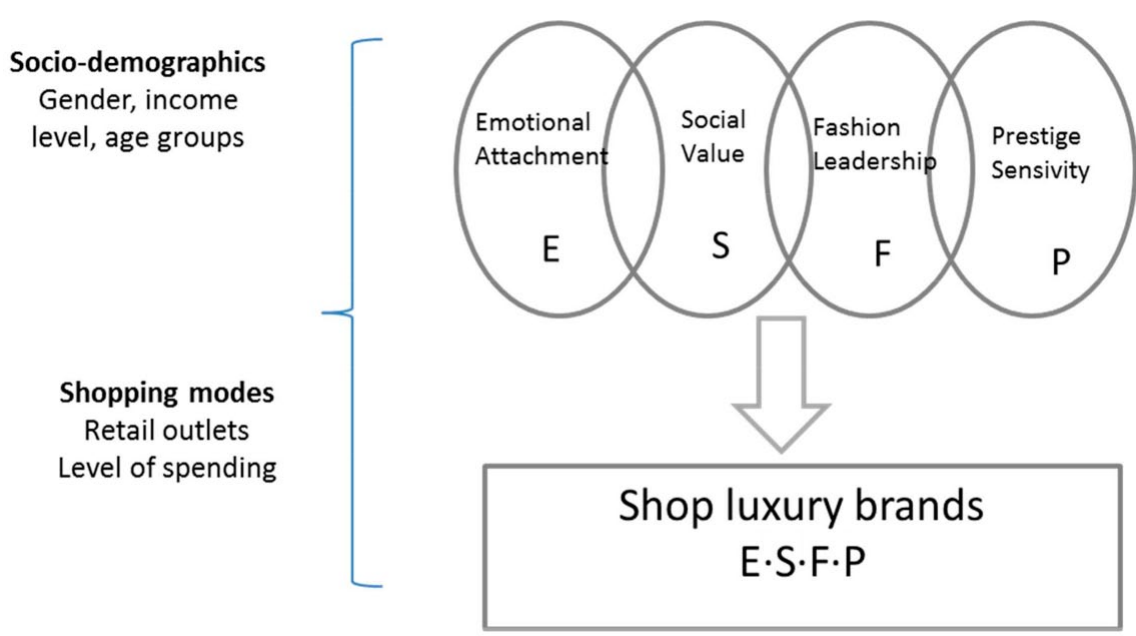

Figure I. Conceptual model.

alternatives to ensure that the full variability of the data is addressed (Rihoux 2006).

The four antecedent conditions outlined in Figure 1 predict that a high degree of membership in the fashion leadership, social value, prestige sensitivity, and emotional attachment sets is positively associated with the assumption of luxury shopping behavior (Veblen 1899). Furthermore, previous research has shown tourism shopping attitudes to be influenced by tourists' social characteristics (Choi et al. 2008; Dubois and Duquesne 1993; Yu and Littrell 2003) and their levels of spending on various products while on vacation (Zaidan 2016). Shopping behavior is also dependent on the retail outlets available (Murphy, Moscardo, and Benckendorff 2013; Zaidan 2016). Accordingly, the effects of these factors were assessed by splitting the sample by sex, age group, income, spending while on vacation, and retail outlets.

It was established that a single value is insufficient to explain tourists' luxury shopping in Hong Kong. More concretely, our research showed that tourists scoring highly in fashion leadership (F), emotional attachment (E), social value (S), and prestige sensitivity $(\mathrm{P})$ are the most likely to shop for luxuries while in Hong Kong. Hence, these four values act together to represent a sufficient condition for luxury shopping, identifying this group of tourists as a perfect or near-perfect subset of luxury consumers, whereas a high score for one value alone is insufficient. The following research proposal was tested in different social and shopping contexts using Boolean algebra.

E.S.F.P $\leq$ Shop $\left(\begin{array}{l}\text { where.represents the logical and } \\ \text { condition, and upper case represents } \\ \text { full membership }\end{array}\right)$.

The proposal results in $4 * 4$ possible combinations, in which each of the sets defined may or may not possess full membership in the configuration. Nonmembership is represented by lowercase, and in this case $\mathrm{OA}=1.00$ concentration.

\section{Methodology}

\section{Measurement}

Questionnaire items were developed based on a thorough literature review. In-depth interviews with five mainland Chinese luxury shoppers were conducted to identify their luxury brand shopping values, preferred items, and preferred country to visit for shopping tourism. A draft questionnaire was developed based on the literature review and then pretested through in-depth interviews with 20 graduate students who were majoring in hospitality and tourism. The questionnaire was initially translated from English into Mandarin by two $\mathrm{PhD}$ students. Two meetings were then held to ensure translation quality by reading each line in English and ascertaining the line in Chinese, and vice versa for back translation. Next, a pilot test was implemented through an online panel survey using 50 mainland Chinese people who had traveled to Hong Kong with the main purpose of shopping and gave some comments about luxury brand items or the definition of a luxury brand. Through these three stages, a final version was decided.

Respondents were invited to complete a questionnaire comprising items contributing to a definition of the four values identified in the literature review. All items in the first part of the questionnaire measured tourist perceptions on a sevenpoint Likert-type scale ranging from strongly disagree (1) to strongly agree (7). Twenty-three items to assess luxury brand shopping values were extracted from the literature (Goldsmith, Freiden, and Kilsheimer 1993; Gutman and Mills 1982; Lichtenstein, Ridgway, and Netemeyer 1993; Sweeney and Soutar 2001). The items included a priori domains such as 
prestige sensitivity, fashion leadership, emotional attachment, and social values. To measure choice sets, three options were proposed: "1: Will not shop for luxury items in Hong Kong," "2: Will maybe shop for luxury items in Hong Kong," and "3: Will shop for luxury items in Hong Kong." The second part of the questionnaire included questions about shopping behavior, such as how much the respondents spend and where they shop, and questions on the respondents' sociodemographic characteristics.

\section{Data Collection}

The study sample comprised mainland Chinese tourists who had traveled to Hong Kong within one year of the start of data collection. To ensure that the sample was restricted to luxury shopping tourists, a screening question was: "Have you bought any luxury brands during a trip to Hong Kong within the past year?" Only those who replied in the affirmative were included in the sampling frame. Data collection for the main survey took place from April 20 to May 2, 2015. The online panel survey company employed to conduct the survey is the largest in mainland China, with approximately 2.5 million panelists. Each respondent who answered the survey was given a coupon as a token reward, which was used as an incentive to increase participation.

An online panel survey was chosen for the following reasons. First, the survey can be completed in a quick duration. Second, the target sample can be selected through screening questions such as shopping region, suitability for luxury brand shopping, and expenditure on shopping. Of the 330 questionnaires collected, 16 which contained multiple missing values or checked only one category on more than 10 items were considered insincere answers. After their exclusion, 314 questionnaires remained for further analysis. To test for nonresponse bias, a further 15 questionnaires were requested from the survey company. Analysis of the 15 questionnaires showed mean values and sociodemographic features similar to those of the respondents.

\section{Data Analysis Methods}

The analysis was developed in three phases. First, exploratory factor analysis (EFA) and within-domain reliability tests were performed, followed by confirmatory factor analysis (CFA) to validate the luxury value scales. Second, a QCA model was implemented to test the research proposal. Third, the proposal was also tested for all shopping modes according to shopping expenditure (i.e., a low, medium, or high level of such expenditure) and retail outlet (i.e., individual shops and surrounding attractions, malls, and shopping centers) and for different sociodemographic profiles (male, female, young adults, adult, and low, medium, or high income level).
Table I. Profile of Respondents.

\begin{tabular}{lc}
\hline Sex & Percentage \\
\hline Male & 61.7 \\
Female & 38.3 \\
Age & \\
Young adults (25-34 years old) & 67.4 \\
Adults (35-44 years old) & 26.9 \\
Seniors (more than 44 years old) & 0.7 \\
Education & \\
College & 17.8 \\
Postgraduate level & 82.2 \\
Occupation & \\
Middle/senior management & 39.6 \\
Professional & 18.4 \\
Retired & 14.2 \\
Other & 27.8 \\
Income & \\
Low (less than US $\$ 16,000)$ & 34.5 \\
Medium (US $\$$ (6,000-24,000) & 32.3 \\
High (more than US $\$ 24,000)$ & 33.2 \\
Length of stay (mean) & 11.4 \\
Number of repeat visits & \\
Main purpose of visit & 3.38 nights (I.4 nights) \\
Shopping & 3.40 times (4.3 times) \\
Leisure & \\
Others (business, visit to friends/ & 50.3 \\
relatives) & 38.3 \\
\hline
\end{tabular}

Note: Values in parentheses indicate median.

\section{Results}

The general characteristics of the sample population, as presented in Table 1, were as follows. The majority (61.7 percent) were women. There were more young adults (67.4 percent) than adults (26.9 percent), and most respondents had a high level of education (82.2 percent held a postgraduate qualification), had good purchasing power (65.5 percent earned more than US\$16,000 per year), and were employed at the professional or senior management level. The respondents visited Hong Kong primarily for shopping (50.3 percent) or leisure (38.3 percent) and spent less than US\$4,000 per trip (72 percent), shopping for the most part in malls and shopping centers. The Chinese luxury shoppers among the respondents were characterized as highly educated senior company workers or professionals in their 30s, a high percentage of whom had traveled mainly for the purpose of shopping, consistent with the characteristics identified in other reports or studies (He 2017; Ngai and Cho 2012; Zhan et al. 2012).

\section{Exploratory Factor Analysis}

EFA using varimax rotation was carried out to derive the underlying factor structure of luxury brand shopping value. 
Table 2. Results of Exploratory Factor Analysis on Luxury Brand Shopping Values.

\begin{tabular}{|c|c|c|c|c|c|}
\hline Domains and items & $\begin{array}{l}\text { Factor } \\
\text { loading }\end{array}$ & M & $S D$ & $\begin{array}{c}\text { Variance } \\
\text { explained (\%) }\end{array}$ & $\begin{array}{l}\text { Cronbach's } \\
\text { alpha }\end{array}$ \\
\hline Emotional attachment & & & & 17.140 & .781 \\
\hline A luxury brand is one that helps me to feel accepted. & 0.657 & 5.725 & 0.934 & & \\
\hline A luxury brand is one that I enjoy. & 0.533 & 5.937 & 0.910 & & \\
\hline A luxury brand is one that I want to use. & 0.744 & 5.889 & 0.868 & & \\
\hline A luxury brand is one that I feel relaxed about using. & 0.509 & 5.851 & 0.922 & & \\
\hline Fashion leadership & & & & 15.279 & .879 \\
\hline $\begin{array}{l}\text { I am aware of fashion trends and want to be one of the first to try } \\
\text { new fashions. }\end{array}$ & 0.806 & 5.671 & 1.118 & & \\
\hline As a fashion leader, I am always the first to try a new fashion. & 0.808 & 5.598 & $\mathrm{I} .124$ & & \\
\hline I am confident in my ability to recognize fashion trends. & 0.588 & 5.816 & 1.026 & & \\
\hline Prestige sensitivity & & & & 13.625 & .739 \\
\hline $\begin{array}{l}\text { My friends will think I am cheap if I consistently buy the lowest } \\
\text { priced product. }\end{array}$ & 0.740 & 5.165 & 1.488 & & \\
\hline $\begin{array}{l}\text { I have purchased an expensive product brand just because I knew } \\
\text { other people would notice. }\end{array}$ & 0.824 & 4.801 & 1.459 & & \\
\hline I think others judge me by the products and brands I buy. & 0.593 & 5.462 & 1.076 & & \\
\hline $\begin{array}{l}\text { Even for a relatively inexpensive product, I think buying a costly } \\
\text { brand is impressive. }\end{array}$ & 0.628 & 5.418 & 1.204 & & \\
\hline Social value & & & & 13.009 & 689 \\
\hline $\begin{array}{l}\text { Clothes are one of the most important ways I have of expressing } \\
\text { my individuality. }\end{array}$ & 0.542 & 5.918 & 0.946 & & \\
\hline A luxury brand makes a good impression on other people. & 0.689 & 5.779 & 0.967 & & \\
\hline A luxury brand brings its owner social approval. & 0.772 & 5.718 & 0.995 & & \\
\hline
\end{tabular}

The items used included five emotional attachment items, six fashion leadership items, nine prestige sensitivity items, and three social value items. Eigenvalues and a scree plot were used to determine the number of factors extracted. However, as factor loadings (less than .45 as recommended by Comrey and Lee 1992) and reliability within the domain (less than .70 as recommended by Nunnally 1978) were low, six items were deleted: "It is important for me to be a fashion leader," "People notice when I buy the most expensive brand of product," "Buying a high-priced brand makes me feel good about myself," "Buying the most expensive brand makes me feel classy," "I enjoy the prestige of buying a high-priced brand," and "I think others make judgments about me based on the kinds of products and brands I buy." Accordingly, these items were excluded from further analysis.

After ruling out these items, rerunning the EFA generated four factors. The KMO of .896 was higher than the 0.6 cutoff criterion recommended by Hair et al. (2010), while Bartlett's test of sphericity was highly significant at the .001 level, indicating the existence of one or more factors. The four-factor solution explained 59.05 percent of the total variance. The four factors extracted were titled emotional attachment, fashion leadership, prestige sensitivity, and social value. The factor structure and labelling were the same as those of the a priori factor model.

The first factor, emotional attachment, contained four items and accounted for 17.14 percent of the total data variance. These items indicated the desire to relax and the pleasure of having what others could not, and the reliability coefficient for this factor was 0.781 . The second factor, fashion leadership, included three items with a reliability coefficient of 0.879 . Four items were incorporated into the prestige sensitivity domain, explaining 13.625 percent of the total variance with a reliability coefficient of .739. The social value domain comprised four items and accounted for 13.01 percent of the total variance with a reliability coefficient of 0.689 . The items indicated that clothes were an expression of individuality and a way to feel happy (Hudders et al. 2014; Peshkova, Urkmez, and Wagner 2016; Rovai 2016b). Table 2 illustrates the factor structure derived from EFA.

\section{Confirmatory Factor Analysis}

CFA was carried out by means of the maximum likelihood method to assess the discriminant and convergent validity of the constructs identified through EFA. The validity of the constructs was also measured by fit indices in CFA in which all constructs were permitted to correlate freely. CFA resulted in a final measurement model with 14 indicators, as illustrated in Tables 3 and 4. As shown in Table 4, the final model results exhibit levels of validity and reliability that can be considered good or very good, with composite reliability far exceeding the minimum recommended limits $(\alpha \geq .70$ and $\rho$ $\geq .70$ ). The average variance extracted (AVE) value obtained also clearly exceeds the reference value $(\geq .50)$ in the literature (Fornell and Larcker 1981). According to Hair et al. (2010), the correlation between variables must be less than .95 , a criterion with which all of our variables comply. 
Table 3. Results of Confirmatory Factor Analysis on Luxury Brand Shopping Values.

\begin{tabular}{|c|c|c|c|c|c|c|}
\hline Item & & Domain & $\begin{array}{l}\text { Standard } \\
\text { estimate }\end{array}$ & SE & CR & $p$ value \\
\hline $\begin{array}{l}\text { I am aware of fashion trends and want to be one of the } \\
\text { first to try new fashions. }\end{array}$ & 4 & Fashion leadership & 0.830 & - & - & - \\
\hline $\begin{array}{l}\text { As a fashion leader, I am always the first to try a new } \\
\text { fashion. }\end{array}$ & $\longleftarrow$ & Fashion leadership & 0.915 & 0.108 & $9.791 * * *$ & .000 \\
\hline I am confident in my ability to recognize fashion trends. & 4 & Fashion leadership & 0.434 & 0.072 & $6.959 * * *$ & .000 \\
\hline I think others judge me by the product brands I buy. & 4 & Prestige sensitivity & 0.912 & - & - & - \\
\hline $\begin{array}{l}\text { My friends will think I am cheap if I consistently buy the } \\
\text { lowest priced products. }\end{array}$ & & Prestige sensitivity & 0.833 & 0.06 & $18.105^{* * *}$ & .000 \\
\hline $\begin{array}{l}\text { I have purchased an expensive product brand just } \\
\text { because I knew other people would notice. }\end{array}$ & & Prestige sensitivity & 0.852 & 0.053 & $18.684 * * *$ & .000 \\
\hline $\begin{array}{l}\text { Even for a relatively inexpensive product, I think buying a } \\
\text { costly brand is impressive. }\end{array}$ & $\longleftarrow$ & Prestige sensitivity & 0.392 & 0.064 & $6.433 * * *$ & .000 \\
\hline A luxury brand brings its owner social approval. & 4 & Social value & 0.472 & - & - & - \\
\hline $\begin{array}{l}\text { A luxury brand makes a good impression on other } \\
\text { people. }\end{array}$ & 4 & Social value & 0.896 & 0.332 & $6.705 * * *$ & .000 \\
\hline $\begin{array}{l}\text { Clothes are one of the most important ways I have of } \\
\text { expressing my individuality. }\end{array}$ & & Social value & 0.784 & 0.28 & $7.065 * * *$ & .000 \\
\hline A luxury brand is one that I want to use. & 4 & Emotional value & 0.996 & - & - & - \\
\hline A luxury brand is one that I feel relaxed about using. & $\longleftarrow$ & Emotional value & 0.494 & 0.105 & $4.547 * * *$ & .000 \\
\hline A luxury brand is one that I enjoy. & $\longleftarrow$ & Emotional value & 0.493 & 0.092 & $4.559 * * *$ & .000 \\
\hline
\end{tabular}

Note: $C R=$ composite reliability; $S E=$ standard error. $* * * p<.001$.

Table 4. Convergent and Discriminant Validity.

\begin{tabular}{|c|c|c|c|c|c|c|c|c|}
\hline Domain & CR & AVE & MSV & ASV & $\begin{array}{l}\text { Prestige } \\
\text { sensitivity }\end{array}$ & $\begin{array}{l}\text { Fashion } \\
\text { leadership }\end{array}$ & $\begin{array}{l}\text { Emotional } \\
\text { value }\end{array}$ & $\begin{array}{l}\text { Social } \\
\text { value }\end{array}$ \\
\hline Prestige sensitivity & 0.849 & 0.601 & 0.042 & 0.027 & 0.775 & & & \\
\hline Fashion leadership & 0.787 & $0.57 I$ & 0.037 & 0.024 & 0.193 & 0.756 & & \\
\hline Emotional attachment & 0.721 & 0.509 & 0.014 & 0.006 & 0.001 & 0.061 & 0.702 & \\
\hline Social value & 0.773 & 0.547 & 0.042 & 0.029 & 0.206 & 0.174 & 0.120 & 0.739 \\
\hline
\end{tabular}

Note: $C R=$ composite reliability; $A V E=$ average variance extracted; $M S V=$ maximum shared variance; $A S V=$ average shared square variance.

Fornell and Larcker (1981) state that AVE can also be used to assess discriminant validity. In that case, the elements of the main diagonal (square root of the AVE) for each construct must show values higher than the correlation coefficients between the different constructs (the elements of the corresponding rows and columns not on the main diagonal) (Barclay, Higgins, and Thompson 1995). The total latent variables in our model satisfy this condition, thereby confirming the existence of discriminant validity and suggesting that the theoretical model fits the data well. Furthermore, the overall fit indices $\left(\chi^{2}=103,875, d f=59\right.$, $\chi^{2} / d f=1.721, p=.000, \mathrm{GFI}=.949, \mathrm{CFI}=.894, \mathrm{TLI}=.859$, RMSEA $=.049)$ are also within the reference values given by Hair et al. (2010), thus confirming the model's goodness of fit.

\section{Fuzzy-Set Analysis}

The luxury values derived were then recorded in a three-point scale to ensure valid calibration. Next, following the suggestions of Ragin (2008), the variables were standardized and assigned membership scores ranging from 0 to 1 . The calibration values adopted to represent the degree of membership in the target set were .05 to indicate full nonmembership, .5 to indicate maximum membership dispersion, and .95 to indicate full membership. Put another way, the fuzzy membership score attaches a truth value to the comment in question (Ragin 2008). The advantage of fuzzy sets over crisp sets is that such data do not lose the variance of the original measure through standardization. Furthermore, introducing a minimum operator (1-A in this study) makes it possible to determine the degree to which an individual experiences a combination of factors, which in this study meant that tourists did not need to be completely in or out of the defined configuration. Although this approach prohibited the use of probabilities to measure the level of membership in subsets of configurations over the overall assessment, Boolean algebraic metrics were used to ensure consistency and coverage. 
Table 5. Calibration Scale for Antecedents of Overall Assessment Sample.

\begin{tabular}{|c|c|c|c|c|c|c|c|c|c|c|c|}
\hline Statistics & Buying & $E$ & $F$ & $P$ & $S$ & $\begin{array}{l}\text { Standard } \\
\text { shopping }\end{array}$ & $\begin{array}{c}\text { Standard } \\
\text { E }\end{array}$ & $\begin{array}{c}\text { Standard } \\
\text { F }\end{array}$ & $\begin{array}{c}\text { Standard } \\
\text { F }\end{array}$ & $\begin{array}{c}\text { Standard } \\
\text { P }\end{array}$ & $\begin{array}{c}\text { Standard } \\
\text { S }\end{array}$ \\
\hline$M$ & 2 & 2 & 2 & 2 & 2 & 0.61 & 0.5 & 0.5 & 0.5 & 0.5 & 0.5 \\
\hline Range & $1-3$ & $1-3$ & $1-3$ & $1-3$ & $1-3$ & $0-1$ & $0-1$ & $0-1$ & $0-1$ & $0-1$ & $0-1$ \\
\hline Mdn (0.5\%) & 3 & 2 & 2 & 2 & 2 & 0.52 & 0.52 & 0.5 & 0.5 & 0.5 & 0.5 \\
\hline$S E$ (mean) & 0.049 & 0.05 & 0.06 & 0.05 & 0.06 & 0.05 & 0.05 & 0.018 & 0.025 & 0.025 & 0.025 \\
\hline$S D$ & 0.88 & 0.89 & 0.85 & 0.87 & 0.88 & 0.81 & 0.89 & 0.328 & 0.44 & 0.45 & 0.44 \\
\hline $.05 \%$ & 1 & I & 1 & 1 & 1 & 1 & 0.03 & 0.02 & 0 & 0 & 0 \\
\hline $.95 \%$ & 3 & 3 & 3 & 3 & 3 & 3 & 1 & I & I & I & I \\
\hline $.99 \%$ & 3 & 3 & 3 & 3 & 3 & 3 & 1 & I & I & I & 1 \\
\hline
\end{tabular}

Note: $E=$ emotional attachment; $F=$ fashion leadership; $P=$ prestige sensitivity; $S=$ social value.

The consistency index acts as a correlation index, meaning that it represents the extent to which a condition determines the outcome in question. Consistency goes further than correlation, as it is a test of sufficiency and necessity (Prado and Woodside 2015). The coverage index in fs QCA, in contrast, acts as the coefficient of determination. Following Ragin (2008), in this article a consistency index equal to or greater than 0.80 and coverage of 0.45 represent a high membership score in the overall assessment of the antecedent items, with a number of cases following an asymmetric sufficiency distribution. Consistency and coverage in Boolean algebra predict high scores for a given combination of $\mathrm{X}$ antecedents (Prado and Woodside 2015).

In this research, the minimum consistency thresholds were tested at 0.80 , with all causal configurations achieving a higher consistency level retained. A set of calibrations was included: the first for the total population $(N=316)$, and the others for the shopping modes (three levels of expenditure and two types of retail outlet) and sociodemographic characteristics of the two age groups, two sex groups, and three income level groups. Details of the calibrations for the simple antecedent conditions appear in Table 5.

A set of configurations were considered in this research. Hence, consistency scores were assigned to reduce the configurations to a more parsimonious solution (Longest and Vaisey 2008). For instance, given the configuration in the research proposal (i.e., E, F, P, S), if both E.F.P.S and E.F.P.S were coded as sufficient, then the configuration would be reduced to F.P.S. This measure allowed us to obtain a logical explanation for the sufficient conditions achieving a particular outcome, thus rendering all of the outcomes more manageable and easier to interpret.

The results include the raw coverage, unique coverage, and consistency membership scores for the causal models exceeding the recommended consistency threshold of 0.80 (Ragin 2008), and focus on the modeling probability of luxury product shopping in Hong Kong through luxury value perceptions. The results presented in Table 6 support the research proposal partially or in full, depending on the social contexts or modes of shopping considered. The table reports the causal configurations of the luxury values for the overall sample, male tourists, female tourists, adult tourists, highspending tourists, high-income tourists, tourists spending large amounts while on vacation, and tourists shopping in individual shops or shopping malls. The 16 initial configurations were reduced to one with a minimum configuration set.

\section{Conclusion and Implications}

This study examined the nature of luxury buying behavior, with a specific focus on Chinese tourist perceptions of luxury shopping visits to Hong Kong. A configurational design comprising four causal conditions leading to shopping for luxury brands was tested to determine the value of these conditions in different social contexts and shopping modes. From a methodological point of view, this study could be considered pioneering in its application of fuzzy-set analysis to the field of tourism.

The results reported herein suggest that only a high degree of membership in all four value sets predicts shopping for luxuries in Hong Kong. Two luxury shopping configurations were identified for male tourists: the first comprising prestige sensitivity and social value, suggesting that social compliance influences the shopping behavior of men and that they are driven by a desire to achieve a certain social status (Chen and Peng 2014; Kurtz 2004; Veblen 1899), and the second comprising fashion leadership and emotional attachment, suggesting that self-image is also a driver pushing men to shop for the latest fashion items (McNeill and Douglas 2011). Previous studies have reported it to also be a driver of shopping behavior for female tourists (Goldsmith, Freiden, and Kilsheimer 1993; Hudders et al. 2014; McRobbie 2013; Wu et al. 2015).

Adult tourists with high scores for fashion leadership and prestige sensitivity were found to be likelier than others to engage in luxury shopping, suggesting that the possession of luxury brands is a way of signaling social status for tourists aged 35 to 44 (Berger and Ward 2010; Wong and Ahuvia 1998). Furthermore, a high degree of emotional attachment was also found to drive shopping behavior in this age group, 
Table 6. Models of Luxury Brand Shopping Value Configurations.

\begin{tabular}{|c|c|c|c|}
\hline Set & Raw coverage & Unique coverage & Solution consistency \\
\hline \multicolumn{4}{|l|}{ Buying luxury brands } \\
\hline$E * F * P * S$ & 0.626 & 0.626 & 0.761 \\
\hline \multicolumn{4}{|l|}{ Total coverage $(0.626)$ | Solution consistency $(0.761)$} \\
\hline \multicolumn{4}{|l|}{ Buying luxury brands/high shopping spending } \\
\hline E*F*p & 0.633 & 0.633 & 0.937 \\
\hline \multicolumn{4}{|l|}{ Total coverage $(0.633)$ | Solution consistency $(0.937)$} \\
\hline \multicolumn{4}{|l|}{ Buying luxury brands/adults } \\
\hline$F * P$ & 0.340 & 0.128 & 0.822 \\
\hline $\mathrm{E}$ & 0.645 & 0.432 & 0.752 \\
\hline \multicolumn{4}{|l|}{ Total coverage $(0.772)$ | Solution consistency $(0.750)$} \\
\hline \multicolumn{4}{|l|}{ Buying luxury brands/high income tourists } \\
\hline$F * P$ & 0.463 & 0.162 & 0.856 \\
\hline$E * P$ & 0.561 & 0.160 & 0.852 \\
\hline \multicolumn{4}{|l|}{ Total coverage $(0.608) \mid$ Solution consistency $(0.83 \mathrm{I})$} \\
\hline \multicolumn{4}{|l|}{ Buying luxury brands/male tourists } \\
\hline $\mathrm{P} * \mathrm{~S}$ & 0.516 & 0.223 & 0.815 \\
\hline$E^{*} \mathrm{~F}$ & 0.477 & 0.284 & 0.862 \\
\hline \multicolumn{4}{|l|}{ Total coverage $(0.600)$ | Solution consistency $(0.828)$} \\
\hline \multicolumn{4}{|l|}{ Buying luxury brands/female tourists } \\
\hline$E * F$ & 0.653 & 0.653 & 0.851 \\
\hline \multicolumn{4}{|l|}{ Total coverage $(0.653)$ | Solution consistency $(0.85$ I) } \\
\hline \multicolumn{4}{|l|}{ Buying luxury brands/shops \& around attractions } \\
\hline$E * F * P * S$ & 0.443 & 0.114 & 0.831 \\
\hline E*P*S & 0.496 & 0.139 & 0.912 \\
\hline E'F*S & 0.588 & 0.230 & 0.932 \\
\hline \multicolumn{4}{|l|}{ Total coverage $(0.555)$ | Solution consistency $(0.890)$} \\
\hline \multicolumn{4}{|l|}{ Buying luxury brands/markets } \\
\hline E & 0.625 & 0.625 & 0.760 \\
\hline Total coverage $(0.625)$ | Solution consistency $(0.760)$ & & & \\
\hline
\end{tabular}

Note: $\mathrm{E}=$ emotional attachment; $\mathrm{F}=$ fashion leadership; $\mathrm{P}=$ prestige sensitivity; $\mathrm{S}=$ social value.

a result that concurs with Yüksel (2007). Luxury has been shown to be dependent on income levels (Amatulli, Guido, and Nataraajan 2015; Correia and Kozak 2012; Park and Reisinger 2009), and it was thus unsurprising in this research to find only high-income tourists engaging in luxury shopping behavior. Eisend and Schuchert-Güler (2006) document a negative correlation between high-income consumers and the purchase of counterfeit products. In the present research, high-income tourists were found to exhibit prestige sensitivity together with social motivations, reflecting their concern with social standing. This finding concurs with Tatzel (2003) who argues that big spenders enjoy spending money and displaying high-status possessions. Furthermore, high-income tourists were also found to value fashion leadership and emotional attachment, suggesting that buying luxuries is also a way of burnishing one's self-image, as previous studies have argued (e.g., Chen and Kim 2013; Danziger 2006; Wong and Ahuvia 1998).

In terms of shopping mode, it seems that shopping in markets is primarily related to emotional values, as they offer an opportunity to interact with the local population (Bian and
Forsythe 2012; Kapferer 2015; Kozak 2015; Kozak et al. 2016). Shopping in the upscale shops and shopping malls considered in this research, in contrast, is associated with fashion and social values, emotions, prestige, and social value, or even emotions alone. In one way or another, shopping in retail outlets has two main drivers: status and selfesteem (Shim and Bickle 1994; Zaidan 2016). Furthermore, the high-spending tourists are likely to shop for luxuries in Hong Kong are driven by emotions and fashion leadership (Choi et al. 2008; Wong 2013).

To summarize, the academic contribution of this research is threefold. First, it attempts to conceptualize luxury values at the theoretical level. Second, from the methodological perspective, it adopts innovative and unrestricted fuzzy-set analysis, which has been proved more robust than other statistical techniques (Ragin 2014), as it allows simultaneous testing of the influence of all of the luxury values on tourist shopping attitudes. Furthermore, despite the advantages of QCA, its application in the tourism context remains limited (D'Urso et al. 2016). Third, it empirically tests the relationship between luxury values and sociodemographic characteristics. Although 
luxury values have been shown to differ by shopping venues and shopping tourists' sociodemographic profiles (e.g., Amatulli, Guido, and Nataraajan 2015; Hudders et al. 2014; Kastanakis and Balabanis 2014; Nwankwo, Hamelin, and Khaled 2014; Park and Reisinger 2009; Stokburger-Sauer and Teichmann 2013), the relationship between those values and profiles has yet to be actively tested. The results of this study are thus expected to contribute to the further development of the luxury shopping concept.

Regarding the implications for practice, the four luxury values considered in this research were together found to establish a sufficient condition to explain luxury shopping behavior. However, under certain sociodemographic conditions, those values are perceived differently. Hofstede's cultural diversity model (Choi, Heo, and Law 2016; Wong and Ahuvia 1998) suggests that collectiveness and family are key influences on individual behavior in Confucianism in general and Chinese culture in particular, which helps to explain why affluent Chinese consumers place more value on products' brands than on the products themselves. The more famous and expensive the brand, the greater the recognition it attracts, which explains the success of such ostentatious luxury brands as Rolex, Luis Vuitton, Armani, Gucci, and Christian Dior in the Chinese market. Respect is a key indicator of social superiority in China, and conspicuous consumption is today the easiest and fastest way to attract respect. The image and awareness of luxury brands among the Chinese public, and the value placed on them, can fulfill Chinese consumers' need to impress others and establish their own superiority. The pursuit of glory and awareness of shame pressure people to succeed in Chinese society. Wearing or using a luxury brand is perceived as bringing glory and respect to individuals, their families, and the wider community, as it is a clear sign of success. It may even lead to being admired and accepted as part of the elite, even in the absence of any personal achievement or political family heritage. This kind of pressure often pushes people toward vanity and a desire to disown their true origins. Veblen $(1899,74)$ characterizes such behavior as follows:

Since the consumption of these more excellent goods [luxury/ expensive goods] is an evidence of wealth, it becomes honorific; and conversely, the failure to consume in due quantity and quality becomes a mark of inferiority and demerit.

Although the results reported here require confirmation through further testing in other cultures, they offer a number of suggestions for enhancing the luxury shopping experience in Hong Kong, at least for mainland Chinese tourists. The study suggests, for example, that Hong Kong could position itself as a center of excellence in promoting luxury brand shopping by catering to market segments motivated by fashion leadership and the pursuit of prestige. As mentioned, the Hong Kong tourism industry is dependent on shopping tourism, and luxury shopping has already become a major driver among a certain group of visitors to the city (Choi, Heo, and Law 2016; He 2017). In this context, the importance of market segmentation could be reconsidered to attract people with specific characteristics, such as middle-aged, high-income, and high-spending groups (Kim, Prideaux, and Chon 2010). This study has some limitations. First, as it was conducted in Hong Kong using mainland Chinese shoppers, its narrow geographic scope limits the generalizability of the findings, and future research should include tourists from different cultures to detect potential differences in their luxury shopping behavior. For such research, the scale used to measure luxury shopping behavior may need to incorporate additional items not considered here to suit other cultures and shopping dynamics. Second, this study identified a link between luxury values and sociodemographic characteristics. However, future research needs to identify whether the perception of luxury value differs according to the type of luxury brand goods, their origin, or the shopping city/country.

\section{Declaration of Conflicting Interests}

The author(s) declared no potential conflicts of interest with respect to the research, authorship, and/or publication of this article.

\section{Funding}

The author(s) received the following financial support for the research, authorship, and/or publication of this article: This work described in this project was fully supported by a grant from The Hong Kong Polytechnic University (G-UA5Z), Hong Kong SAR China, and Fundação para a Ciência e a Tecnologia (Grant UID/ ECO/04007/2013) and FEDER/COMPETE (POCI-01-0145FEDER-007659), both in Portugal.

\section{References}

Agrusa, J., S. S. Kim, and K. C. Wang. 2011. "Mainland Chinese Tourists to Hawaii: Their Characteristics and Preferences." Journal of Travel and Tourism Marketing 28 (2): 261-78.

Amatulli, C., G. Guido, and R. Nataraajan. 2015. "Luxury Purchasing among Older Consumers: Exploring Inferences about Cognitive Age, Status, and Style Motivations.” Journal of Business Research 68 (9): 1945-52.

Bain \& Company. 2012. "Mercado de luxo brasileiro crescerá até 25\% nos próximos cinco anos, segundo projeções da." http:// www.bain.com/offices/sãopaulo/pt/press/bain-projects-globalluxury-goods-marketwill-grow-ten-percent-in-2012.aspx.

Bakker, M. 2005. "Luxury and Tailor-Made Holidays." Travel and Tourism Analyst 20: 1-47.

Barclay, D., C. Higgins, and R. Thompson. 1995. "The Partial Least Squares (PLS) Approach to Causal Modeling: Personal Computer Adoption and Use as an Illustration." Technology Studies 2: 285-309.

Bearden, W. O., and M. J. Etzel. 1982. "Reference Group Influence on Product and Brand Purchase Decisions." Journal of Consumer Research 9 (2): 183-94.

Berger, J., and M. Ward. 2010. "Subtle Signals of Inconspicuous Consumption." Journal of Consumer Research 37 (4): 555-69. 
Bian, Q., and S. Forsythe. 2012. "Purchase Intention for Luxury Brands: A Cross-Cultural Comparison." Journal of Business Research 65 (10): 1443-51.

Bonetti, F. 2014. "Italian Luxury Fashion Brands in China: A Retail Perspective." International Review of Retail, Distribution and Consumer Research 24 (4): 453-77.

Brondoni, S. M., and E. Arrigo. 2015. "Ouverture de 'Fashion and Luxury Management."' SYMPHONYA Emerging Issues in Management 4: 1-8.

Buckley, P. J., J. Clegg, and H. Tan. 2006. “Cultural Awareness in Knowledge Transfer to China-The Role of Guanxi and Mianzi." Journal of World Business 41 (3): 275-88.

Cardoso, C., and L. Ferreira. 2000. "The Effects of European Economic Integration on Tourism: Challenges and Opportunities for Portuguese Tourism Development." International Journal of Contemporary Hospitality Management 12 (7): 401-9.

Chadha, R., and P. Husband. 2006. The Cult of The Luxury Brand, Inside Asia's Love Affair with Luxury. London: Nicholas Brealey.

Chan, W. Y., C. K. To, and W. C. Chu. 2015. "Materialistic Consumers Who Seek Unique Products: How Does Their Need for Status and Their Affective Response Facilitate the Repurchase Intention of Luxury Goods?" Journal of Retailing and Consumer Services 27:1-10.

Chen, A., and N. Peng. 2014. "Examining Chinese Consumers' Luxury Hotel Staying Behavior." International Journal of Hospitality Management 39:53-56.

Chen, J., and S. Y. Kim. 2013. "A Comparison of Chinese Consumers' Intentions to Purchase Luxury Fashion Brands for Self-Use and for Gifts." Journal of International Consumer Marketing 25 (1): 29-44.

Choi, M. J., C. Y. Heo, and R. Law. 2016. "Developing a Typology of Chinese Shopping Tourists: An Application of the Schwartz Model of Universal Human Values." Journal of Travel and Tourism Marketing 33 (2): 141-51.

Choi, T. M., S. C. Liu, K. M. Pang, and Pui-Sze Chow. 2008. "Shopping Behaviors of Individual Tourists from the Chinese Mainland to Hong Kong." Tourism Management 29 (4): 811-20.

Chu, C. H., and Y. J. Guo. 2015. "Developing Similarity-Based IPA under Intuitionistic Fuzzy Sets to Assess Leisure Bikeways." Tourism Management 47:47-57.

Comrey, A., and H. Lee. 1992. A First Course in Factor Analysis. Hillsdale, NJ: Erlbaum.

Correia, A., and M. Kozak. 2012. "Exploring Prestige and Status on Domestic Destinations: The Case of Algarve." Annals of Tourism Research 39 (4): 1951-67.

Correia, A., and M. Kozak. 2016. "Shopping Tourism." In Encyclopedia of Tourism, edited by J. Jafari and H. Xiao, 56768. Chur, Switzerland, Springer.

Correia, A., M. Kozak, and S. Kim. 2017. "Luxury Shopping Orientations of Mainland Chinese Tourists in Hong Kong: Their Shopping Destination." Tourism Economics. Published online August 21. doi:10.1177/1354816617725453.

Correia, A., M. Kozak, and H. Reis. 2016. "Conspicuous Consumption of the Elite: Social and Self-Congruity in Tourism Choices." Journal of Travel Research 55 (6): 738-50.

Danziger, P. 2006. Shopping: Why We Love It and How Retailers Can Create the Ultimate Customer Experience. Chicago: Kaplan.
Degen, R. J. 2009. “Opportunity for Luxury Brands in China.” IUP Journal of Brand Management 6 (3/4): 75-85.

De Meur, G., and B. Rihoux. 2002. L'Analyse Quali-quantitative Comparée (AQQCQCA): Approche, Techniques et applications en sciences humaines. Louvain-la-Neuve: AcademiaBruylant.

Dubois, B., and P. Duquesne. 1993. "The Market for Luxury Goods: Income versus Culture." European Journal of Marketing 27 (1): 35-44.

D’Urso, P., M. Disegna, R. Massari, and L. Osti. 2016. "Fuzzy Segmentation of Postmodern Tourists." Tourism Management 55:297-308.

Eisend, M., and P. Schuchert-Güler. 2006. "Explaining Counterfeit Purchases: A Review and Preview." Academy of Marketing Science Review 2006 (12). http://search.proquest.com/ docview/200799861?pq-origsite $=$ gscholar.

Euromonitor International. 2015. "2015 WTM Global Trends Report.” http://go.euromonitor.com/event-wtm-global-trendsreport-2015.html.

Fornell, C., and D.F. Larcker. 1981. "Evaluating Structural Equation Models with Unobservable Variables and Measurement Error." Journal of Marketing Research 18 (1): 39-50.

Fotiadis, A., S. S. Yeh, and T. C. T. Huan. 2016. "Applying Configural Analysis to Explaining Rural-Tourism Success Recipes." Journal of Business Research 69 (4): 1479-83.

Gao, H., S. Huang, and G. Brown. 2017. "The Influence of Face on Chinese Tourists' Gift Purchase Behaviour: The Moderating Role of the Gift Giver-Receiver Relationship." Tourism Management 62: 97-106.

Goldsmith, R. E., J. B. Freiden, and J. C. Kilsheimer. 1993. "Social Values and Female Fashion Leadership: A Cross-Cultural Study." Psychology \& Marketing 10 (5): 399-412.

Goldsmith, R. E., J. R. Heitmeyer, and J. B. Freiden. 1991. "Social Values and Fashion Leadership." Clothing and Textiles Research Journal 10 (1): 37-45.

Gutman, J., and M. K. Mills, 1982. "Fashion Life-Style, SelfConcept, Shopping Orientation, and Store Patronage-An Integrative Analysis.” Journal of Retailing 58 (2): 64-86.

Hair, J. F., W. C. Black, B. J. Babin, and R. E. Anderson. 2010. Multivariate Data Analysis. 7th ed. Englewood Cliffs, NJ: Prentice Hall.

Hamelin, N., and P. Thaichon. 2016. "Consumer Motives and Impact of Western Media on the Moroccan Luxury Buyer." Journal of Retailing and Consumer Services 32:164-70.

He, L. 2017. "The Rise and Rise of China's Modern-Day Yuppies, and What It Means for Consumption." South China Morning Post. http://www.scmp.com/business/companies/article/2092052/ rise-and-rise-chinas-modern-day-yuppies-and-what-it-means.

Holbrook, M. B., and E. C. Hirschman. 1982. "The Experiential Aspects of Consumption: Consumer Fantasies, Feelings, and Fun.” Journal of Consumer Research 9 (2): 182-90.

Hong Kong Tourism Board. 2015. "Visitor Profile Report-2015." Hong Kong: Hong Kong Tourism Board.

Hsu, C. H., and S. S. Huang. 2016. "Reconfiguring Chinese Cultural Values and Their Tourism Implications." Tourism Management 54:230-42.

Hudders, L., C. De Backer, M. Fisher, and P. Vyncke. 2014. "The Rival Wears Prada: Luxury Consumption as a Female Competition Strategy." Evolutionary Psychology 12 (3): 570-87. 
Ikkos, A. 2003. "Luxury Tourism: A Matter for All, Not Just Hotels." http://www.gbrconsulting.gr/articles/Luxury\%20Tourism.

Jain, V., S. Roy, and A. Ranchhod. 2015. "Conceptualizing Luxury Buying Behavior: The Indian Perspective." Journal of Product \& Brand Management 24 (3): 211-28.

Jansen-Verbeke, M. 1991. "Leisure Shopping: A Magic Concept for the Tourism Industry?" Tourism Management 12 (1): 9-14.

Jansen-Verbeke, M. 1994. "The Synergy between Shopping and Tourism: The Japanese Experience." In Global Tourism: The Next Decade, edited by W. F. Teobald, 347-62. Oxford: Butterworth-Heinemann.

Jin, B., and B. Sternquist. 2004. "Shopping Is Truly a Joy." Service Industries Journal 24 (6): 1-18.

Josiam, B. M., T. R. Kinley, and Y. K. Kim. 2005. "Involvement and the Tourist Shopper: Using the Involvement Construct to Segment the American Tourist Shopper at the Mall." Journal of Vacation Marketing 11 (2): 135-54.

Kaiser, S. B. 1990. The Social Psychology of Clothing. 2nd ed. New York: Macmillan.

Kamal, S., S. C. Chu, and M. Pedram. 2013. "Materialism, Attitudes, and Social Media Usage and Their Impact on Purchase Intention of Luxury Fashion Goods among American and Arab Young Generations." Journal of Interactive Advertising 13 (1): 27-40.

Kapferer, J. N. 2015. Kapferer on Luxury: How Luxury Brands Can Grow yet Remain Rare? London: Kogan Page.

Kapferer, J. N., and V. Bastien. 2009. "The Specificity of Luxury Management: Turning Marketing Upside Down.” Journal of Brand Management 16 (5): 311-22.

Kastanakis, M. N., and G. Balabanis. 2012. "Between the Mass and the Class: Antecedents of the 'Bandwagon' Luxury Consumption Behavior.” Journal of Business Research 65 (10): 1399-1407.

Kastanakis, M. N., and G. Balabanis. 2014. "Explaining Variation in Conspicuous Luxury Consumption: An Individual Differences' Perspective.” Journal of Business Research 67 (10): 2147-54.

Kim, A. J., and E. Ko. 2012. "Do Social Media Marketing Activities Enhance Customer Equity? An Empirical Study of Luxury Fashion Brand." Journal of Business Research 65 (10): 1480-86.

Kim, S., and B. McKercher. 2011. "The Collective Effect of National Culture and Tourist Culture on Tourist Behavior." Journal of Travel and Tourism Marketing 28 (2): 145-64.

Kim, S., B. Prideaux, and K. Chon. 2010. "A Comparison of Results of Three Statistical Methods to Understand the Determinants of Festival Participants' Expenditures." International Journal of Hospitality Management 29 (2): 297-307.

Kim, S., D. Timothy, and J. Hwang. 2011. "Understanding Japanese Tourists' Shopping Tourists Using Destination Tree Analysis." Tourism Management 32 (3): 544-54.

Kozak, M. 2015. "Bargaining Behavior and the Shopping Experiences of British Tourists on Vacation." Journal of Travel and Tourism Marketing 33 (3): 313-25.

Kozak, M., A. Correia, and G. Del Chiappa. 2016. "The Propensity to Bargain while on a Vacation." Tourism Economics 23 (1): 150-67.

Kurtz, R. 2004. "Marketing Travel to the Affluent." In The Complete 21st Century Travel and Hospitality Marketing Handbook, edited by B. Dickinson and A. Vladimir, 525-36. Upper Saddle River, NJ: Prentice Hall.

Lee, J. E., and B. Watkins. 2016. "YouTube Vloggers' Influence on Consumer Luxury Brand Perceptions and Intentions." Journal of Business Research 69: 5753-60.
Leibenstein, H. 1950. "Bandwagon, Snob, and Veblen Effects in the Theory of Consumers' Demand." Quarterly Journal of Economics 64 (2): 183-207.

Li, M. 2015. "Global Consumer Behaviors in Luxury Goods Market." In Global Marketing Strategies for the Promotion of Luxury Goods, edited by F. Mosca and R. Gallo, 1-22. Hersey, PA: IGI Global.

Li, X. R., C. Lai, R. Harrill, S. Kline, and L. Wang. 2011. "When East Meets West: An Exploratory Study on Chinese Outbound Tourists' Travel Expectations." Tourism Management 32 (4): 741-49.

Lichtenstein, D. R., N. M. Ridgway, and R. G. Netemeyer. 1993. "Price Perceptions and Consumer Shopping Behavior: A Field Study." Journal of Marketing Research 30 (2): 234-45.

Littrell, M. A., R. C. Paige, and K. Song, 2004. "Senior Travellers: Tourism Activities and Shopping Behaviours." Journal of Vacation Marketing 10 (4): 348-62.

Longest, K. C., and S. Vaisey. 2008. "Fuzzy: A Program for Performing Qualitative Comparative Analyses (QCA) in Stata." Stata Journal 8 (1): 79.

Lu, X. P. 2008. Elite China: Luxury Consumer Behavior in China. New York: John Wiley.

Luck, E., G. Muratovski, and L. Hedley. 2014. "Co-branding strategies for Luxury Fashion Brands: Missoni for Target." Global Fashion Brands: Style, Luxury \& History 1 (1): 41-56.

Mason, R. 1981. Conspicuous Consumption: A Study of Exceptional Consumer Behaviour. Farnborough, UK: Gower.

McNeill, L. S., and K. Douglas. 2011. "Retailing Masculinity: Gender Expectations and Social Image of Male Grooming Products in New Zealand." Journal of Retailing and Consumer Services 18 (5): 448-54.

McRobbie, A. 2013. "Fashion Matters Berlin: City-Spaces, Women's Working Lives, New Social Enterprise?" Cultural Studies 27 (6): 982-1010.

Mendel, J. M., and M. M. Korjani. 2013. "Theoretical Aspects of Fuzzy Set Qualitative Comparative Analysis (fsQCA)." Information Sciences 237:137-61.

Morganosky, M. A. 1990. "Store and Brand Type Influences on the Perception of Apparel Quality: A Congruity Theory Approach." Clothing and Textiles Research Journal 9 (1): 45-49.

Moschis, G. P. 1976. "Social Comparison and Informal Group Influence." Journal of Marketing Research 13 (3): 237-44.

Murphy, L., G. Moscardo, and P. Benckendorff. 2013. "Understanding Tourist Shopping Village Experiences on the Margins." In Tourism and Souvenirs: Global Perspectives from the Margins, edited by J. Cave, L. Jolliffe, and T. Baum, 132-46. Bristol, UK: Channel View.

Ngai, J., and E. Cho. 2012. "The Young Luxury Consumers in China." Young Consumers 13 (3): 255-66.

Nunnally, J. 1978. Psychometric Theory. 2nd ed. New York: McGraw-Hill.

Nwankwo, S., N. Hamelin, and M. Khaled. 2014. "Consumer Values, Motivation and Purchase Intention for Luxury Goods." Journal of Retailing and Consumer Services 21 (5): 735-44.

Papatheodorou, A., and N. Pappas. 2017. "Economic Recession, Job Vulnerability, and Tourism Decision Making: A Qualitative Comparative Analysis." Journal of Travel Research 56:663-77.

Park, C. W., and V. P. Lessig. 1977. "Students and Housewives: Differences in Susceptibility to Reference Group Influence." Journal of Consumer Research 4 (2): 102-10. 
Park, H. J., N. J. Rabolt, and K. Sook Jeon. 2008. "Purchasing Global Luxury Brands among Young Korean Consumers." Journal of Fashion Marketing and Management 12 (2): 244-59.

Park, K. S., and Y. Reisinger. 2009. "Cultural Differences in Shopping for Luxury Goods: Western, Asian, and Hispanic Tourists." Journal of Travel and Tourism Marketing 26 (8): 762-77.

Peshkova, A., T. Urkmez, and R. Wagner. 2016. "Intimacy of the Russian Upper Middle Class with Luxury Fashion." Journal of Global Scholars of Marketing Science 26 (2): 152-73.

Prado, A. M., and A. G. Woodside. 2015. "Deepening Understanding of Certification Adoption and Non-adoption of InternationalSupplier Ethical Standards." Journal of Business Ethics 132 (1): $105-25$.

Ragin, C. C. 1987. The Comparative Method. Moving Beyond Qualitative and Quantitative Strategies. Berkeley, Los Angeles and London: University of California Press.

Ragin, C. C., and B. Rihoux. 2004. "Qualitative Comparative Analysis (QCA): State of the Art and Prospects." Qualitative Methods: Newsletter of the American Political Science Association Organized Section on Qualitative Methods 2(2): $3-13$

Ragin, C. C. 2008. Redesigning Social Inquiry: Fuzzy Sets and Beyond. Vol. 240. Chicago: University of Chicago Press.

Ragin, C. C. 2014. The Comparative Method: Moving Beyond Qualitative and Quantitative Strategies. Berkeley: University of California Press.

Richins, M. L. 1994. "Special Possessions and the Expression of Material Values." Journal of Consumer Research 21 (3): 522-33.

Rihoux, B. 2003. "Bridging the Gap between the Qualitative and Quantitative Worlds? A Retrospective and Prospective View on Qualitative Comparative Analysis." Field Methods 15 (4): 351-65.

Rihoux, B. 2006. "Qualitative Comparative Analysis (QCA) and Related Systematic Comparative Methods Recent Advances and Remaining Challenges for Social Science Research." International Sociology 21 (5): 679-706.

Rovai, S. 2016a. "Chinese Outbound Shopping Tourism: A MarketDriven Approach for the Luxury and Fashion Industry." SYMPHONYA Emerging Issues in Management 1:56-63.

Rovai, S. 2016b. Luxury the Chinese Way: New Competitive Scenario. New York: Palgrave Macmillan.

Shim, S., and M. C. Bickle. 1994. "Benefit Segments of the Female Apparel Market: Psychographics, Shopping Orientations, and Demographics." Clothing and Textiles Research Journal 12 (2): 1-12.

Shukla, P., and K. Purani. 2012. "Comparing the Importance of Luxury Value Perceptions in Cross-National Contexts." Journal of Business Research 65 (10): 1417-24.

Souiden, N., B. M'Saad, and F. Pons. 2011. “A Cross-Cultural Analysis of Consumers' Conspicuous Consumption of Branded Fashion Accessories." Journal of International Consumer Marketing 23 (5): 329-43.

Sternquist, B., S. E. Byun, and B. Jin. 2004. "The Dimensionality of Price Perceptions: A Cross-Cultural Comparison of Asian Consumers." International Review of Retail, Distribution and Consumer Research 14 (1): 83-100.

Stokburger-Sauer, N. E., and K. Teichmann. 2013. "Is Luxury Just a Female Thing? The Role of Gender in Luxury Brand Consumption.” Journal of Business Research 66 (7): 889-96.
Sweeney, J. C., and G. N. Soutar. 2001. "Consumer Perceived Value: The Development of a Multiple Item Scale." Journal of Retailing 77 (2): 203-20.

Tatzel, M. 2003. "The Art of Buying: Coming to Terms with Money and Materialism.” Journal of Happiness Studies 4 (4): 405-35.

Truong, Y., R. McColl, and P. J. Kitchen. 2009. "New Luxury Brand Positioning and the Emergence of Masstige Brands." Journal of Brand Management 16 (5): 375-82.

Tsai, W. S., Q. Yang, and Y. Liu. 2013. "Young Chinese Consumers' Snob and Bandwagon Luxury Consumption Preferences." Journal of International Consumer Marketing 25 (5): 290-304.

UNWTO. 2015. "UNWTO Tourism Highlights." http://www.eunwto.org/doi/pdf/10.18111/9789284416899.

UNWTO. 2016. “UNWTO Tourism Highlights.” Madrid: UNWTO.

Veblen, T. 1899. "The Barbarian Status of Women." American Journal of Sociology 4 (4): 503-14.

Vickers, J. S., and F. Renand. 2003. "The Marketing of Luxury Goods: An Exploratory Study-Three Conceptual Dimensions.” Marketing Review 3 (4): 459-78.

Vigneron, F., and L. W. Johnson. 1999. "A Review and a Conceptual Framework of Prestige-Seeking Consumer Behavior." Academy of Marketing Science Review 99 (1): 1-15.

Wen, C. H., S. H. Liao, W. L. Chang, and P. Y. Hsu. 2012. "Mining Shopping Behavior in the Taiwan Luxury Products Market." Expert Systems with Applications 39 (12): 11257-68.

Wiedmann, K.P., N. Hennigs, and A. Siebels. 2007a. "Understanding and Measuring Luxury Value: A Multidimensional Model of Consumers' Luxury Perception." In 2007 AMA Winter Educators' Conference Marketing Theory and Applications, edited by A. L. Dickson and K. A. Machleit, 393-95. Chicago: American Marketing Association.

Wiedmann, K. P., N. Hennigs, and A. Siebels. 2007b. "Value-Based Segmentation of Luxury Consumption Behavior." Psychology and Marketing 26:625-51.

Wong, I. K. A. 2013. "Mainland Chinese Shopping Preferences and Service Perceptions in the Asian Gaming Destination of Macau." Journal of Vacation Marketing 19 (3): 239-51.

Wong, N. Y., and A. C. Ahuvia. 1998. "Personal Taste and Family Face: Luxury Consumption in Confucian and Western Societies." Psychology and Marketing 15 (5): 423-41.

Wong, Y. 2007. Succeeding Like Success: The Affluent Consumers of Asia. New York: John Wiley.

Woodside, A. G. 2013. "Moving beyond Multiple Regression Analysis to Algorithms: Calling for Adoption of a Paradigm Shift From Symmetric to Asymmetric Thinking in Data Analysis and Crafting Theory." Journal of Business Research 66 (4): 463-72.

Woodside, A. G., S. Y. Hsu, and R. Marshall. 2011. "General Theory of Cultures' Consequences on International Tourism Behavior." Journal of Business Research 64 (8): 785-99.

Woodside, A. G., C. Prentice, and A. Larsen. 2015. "Revisiting Problem Gamblers' Harsh Gaze on Casino Services: Applying Complexity Theory to Identify Exceptional Customers." Psychology \& Marketing 32 (1): 65-77.

Workman, J. E., and L. K. Kidd. 2000. "Use of the Need for Uniqueness Scale to Characterize Fashion Consumer Groups." Clothing and Textiles Research Journal 18 (4): 227-36.

Wu, M. S. S., I. Chaney, C. H. S. Chen, B. Nguyen, and T. Melewar. 2015. "Luxury Fashion Brands: Factors Influencing Young Female Consumers' Luxury Fashion Purchasing in Taiwan." Qualitative Market Research 18 (3): 298-319. 
Yang, W., and A. Mattila. 2014. "Do Affluent Customers Care When Luxury Brands Go Mass? The Role of Product Type and Status Seeking on Luxury Brand Attitude.” International Journal of Contemporary Hospitality Management 26 (4): 526-43.

Yang, W., and A. S. Mattila. 2017. "The Impact of Status Seeking on Consumers' Word of Mouth and Product Preference: A Comparison Between Luxury Hospitality Services and Luxury Goods." Journal of Hospitality \& Tourism Research 41 (1): 3-22.

Yoo, J., and M. Park. 2016. "The Effects of E-Mass Customization on Consumer Perceived Value, Satisfaction and Loyalty toward Luxury Brands." Journal of Business Research 69:5775-84.

Yu, H., and M. A. Littrell. 2003. "Product and Process Orientations to Tourism Shopping." Journal of Travel Research 42 (2): 140-50.

Yüksel, A. 2007. "Tourist Shopping Habitat: Effects on Emotions, Shopping Value and Behaviours." Tourism Management 28 (1): 58-69.

Zaidan, E. A. 2016. "Tourism Shopping and New Urban Entertainment: A Case Study of Dubai." Journal of Vacation Marketing 22 (1): 29-41.

Zhan, L., and Y. He. 2012. "Understanding Luxury Consumption in China: Consumers' Perceptions of Best-Known Brands." Journal of Business Research 10:1452-60.
Zhang, B., and J. H. Kim. 2013. "Luxury Fashion Consumption in China: Factors Affecting Attitude and Purchase Intent." Journal of Retailing and Consumer Services 20 (1): 68-79.

Zhu, D., H. Xu, and L. Jiang. 2016. "Behind Buying: The Chinese Gaze on European Commodities." Asia Pacific Journal of Tourism Research 21 (3): 293-311.

\section{Author Biographies}

Antonia Correia is professor of Tourist Behaviour and Tourism Economics, University of Algarve and dean of the School of Tourism, Sports and Hospitality, Universidade Europeia, Portugal. Her main research interests focus on consumer behaviour, tourism economics and modelling.

Metin Kozak is professor of Tourism in the School of Tourism, Dokuz Eylul University, Turkey. He holds both Master's and PhD degrees in tourism management. His research focuses on consumer behaviour, benchmarking, destination management and marketing, and sustainability.

Seongseop (Sam) Kim is associate professor of the School of Hotel and Tourism Management, The Hong Kong Polytechnic University, Hong Kong SAR, China. His main research interests include tourist behavior, film tourism, convention/event management, destination marketing, and economic psychology. 